\title{
Biografía
}

\section{Dr. Francisco Bolaños Araya}

Escribir sobre el Dr. Francisco Bolaños Araya es, para mí, confortante y a la vez inquietante, porque fui su amigo, su discípulo y su admirador, circunstancias que podrían sesgar mis opiniones. Al hacerlo, pretendo que los médicos jóvenes conozcan a un profesional de gran vocación quien, en un pequeño hospital de madera, y en una Costa Rica que era muy diferente a la actual, donde los médicos no contábamos con: resonancias magnéticas, tomografías computarizadas, ultrasonidos ni tantos otros medios que hoy tenemos, enfrentaba los problemas de sus pacientes como un líder, que sabía motivar a su personal para que se actualizara y cumpliera al máximo con sus labores, lo que llevó a la institución que dirigía, a hacer procedimientos innovadores en el país. Era un lector incansable de las revistas médicas, por lo que estaba al tanto de los adelantos de la Medicina que compartía con sus colegas.

Lo conocí en 1958, cuando él era director del Hospital San Vicente de Paul, en la ciudad de Heredia, y yo llegué a ese centro como asistente de Cirugía General. A pesar de tener él un buen entrenamiento en esa rama, disfrutaba asistiendo a los cirujanos jóvenes, como era mi caso. Durante las intervenciones, siempre aprovechaba algunos momentos para conversar, así pude apreciar su excepcional

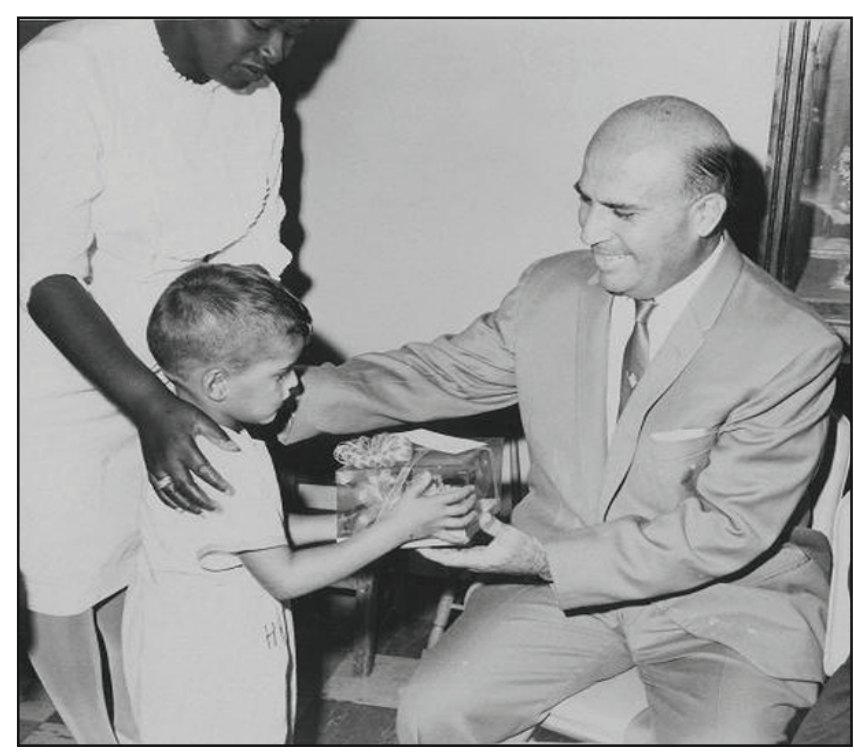

técnica por primera vez en el país. Actualmente, es una de las más usadas en Costa Rica y en el mundo.

Otro ejemplo que muestra su manera recta de actuar, fue cuando el Dr. Rodrigo Araya llegó al hospital, con un muy buen entrenamiento en Cirugía General. El padre del Dr. Araya, cuando fue presidente de la Junta de Protección del Hospital de Heredia, había tenido discrepancias con el Dr. Bolaños, 10 que propició roces entre el cirujano recién llegado y el director. Consciente de lo valioso que era para el hospital un cirujano como el Dr. Araya, delegó en mí la organización del Servicio de Cirugía y fue con esa actitud de hombre recto, que formamos un equipo quirúrgico que permitió a un cirujano joven efectuar complicadas operaciones de cirugía general, las cuales beneficiaron a los pacientes y brindaron prestigio al hospital.

Trabajador insigne, entraba todos los días con el alba a la institución y revisaba a cada uno de los pacientes internados, para tener una idea global del centro; cuando encontraba alguna acción con la que no estaba de acuerdo, dejaba una sugerencia para el médico tratante.

Recuerdo que en múltiples ocasiones me solicitó que iniciáramos las operaciones modestia, pues nunca hacía alarde de su amplia sabiduría, nunca se creía dueño de la verdad, y siempre estaba dispuesto a escuchar todos los argumentos antes de tomar sus decisiones.

A manera de ejemplo, quisiera relatar algunos episodios que muestran su manera de ser, para que se formen una idea de su personalidad. Yo, además de trabajar en el hospital de Heredia, lo hacía también en el Hospital San Juan de Dios, donde habíamos operado a varios pacientes que tenían un megacolon agangliónico con la técnica del Dr. Swenson, la cual era muy difícil de realizar y nos había producido serias complicaciones. En 1968 apareció en la revista, Annales de chirurgie infantile, la técnica del Dr. Duhamel, mucho más sencilla. Como yo no había podido convencer a mi jefe de servicio del Hospital San Juan de Dios para que la probáramos, le enseñé el artículo al Dr. Bolaños, quien inmediatamente después de leerlo me dijo que le parecía excelente, y que el tenía un paciente de 14 años con el padecimiento, a quien podíamos operar en el hospital. Fue así como bajo su aprobación y con su asistencia, se hizo esta a las 5:00 a.m., por lo que las hermanas franciscanas, que se encargaban del centro, en varias oportunidades se privaron de sus rezos matinales para complacerlo. Eso, sin embargo, no era impedimento para que ese mismo día operáramos alguna emergencia, incluso avanzada la noche. Todo esto, cuando ya era un hombre maduro -sin cobrar horas extra, ni disponibilidad-, pues no concebía esos procederes. Discípulo del cardenal Mercier, junto con el Dr. Rafael Ángel Calderón Guardia, había aprendido en Europa lo que era la responsabilidad social del médico, y la aplicaba.

En ese tiempo los hospitales pertenecían a la Dirección General de Asistencia Médico Social, y eran administrados por juntas de protección locales, financiadas con dinero de la lotería y con subvenciones del gobierno. Como es lógico suponer, el dinero era escaso.

Durante su formación había recibido cursos de lógica y de ética, dos campos de sus conocimientos, que aplicaba 
constantemente, sin lograr comprender cómo estas materias habían dejado de formar parte del currículum de los médicos. Al aplicarlos, decía, que ante las emergencias hay que actuar con calma y que es muy importante tomarse unos minutos para analizar las opciones y escoger la mejor solución.

Siempre preocupado por buscar la excelencia, demandaba de los miembros de la Junta de Protección Social, la compra de suministros de alta tecnología.

Conocedor de que la medicina es algo muy complejo como para que la ejerza una sola persona, supo formar un equipo en aquel sencillo hospital, con un grupo de excelentes profesionales, entre los que recuerdo a los doctores Juan Rafael León, Salomón Faschler, Carlos Cordero, Roberto Vargas - Realizábamos reuniones durante las noches, cada 15 días, para discutir temas médicos de actualidad, y analizábamos a los pacientes de los distintos servicios. Motivados por su dedicación, sinceridad y amor a las personas, nos estimuló a brindar a los enfermos una atención que no solo era muy buena, sino también humana y comprensiva, algo que se ha perdido en muchos profesionales...

Sus estudios de Medicina los realizó en la Universidad de Lovaina, Bélgica adonde llega el 1928 y se gradúa con honores en 1934, para regresar a Costa Rica en 1935. Trabajó algunos años en el Sanatorio Durán y luego en los hospitales San Juan de Dios y Calderón Guardia; fue nombrado director del Hospital San Vicente de Paul, de Heredia, el 1 de mayo de 1940, y ahí trabajó hasta su retiro, el 31 de agosto de 1965.

Contrajo matrimonio con María del Carmen Solera Flores y tuvieron dos hijas: María de los Ángeles y Marta Eugenia.

El Dr. Francisco Bolaños Araya es un claro ejemplo de un médico para quien resultaba evidente lo que era trabajar en equipo, valorando la calidad de los servicios que prestaban sus miembros, sin descuidar en ningún momento el costo, y sin sacrificar jamás la excelencia. Para Paco, como lo llamábamos sus amigos, lo más importante era el paciente, y a él era a quien había que dedicarle la mayor parte del tiempo. No puedo imaginármelo frente al engorroso papeleo administrativo al que ahora se encuentran obligados los médicos...

Murió el 18 de febrero de 1997, y ese día el país perdió a un excelente profesional, a un hombre sencillo al máximo, que nunca buscó que lo alabaran, y que vivió predicando con su ejemplo.
Dr. Carlos Arrea Baixench Presidente Academia Nacional de Medicina Editor Acta Médica Costarricense

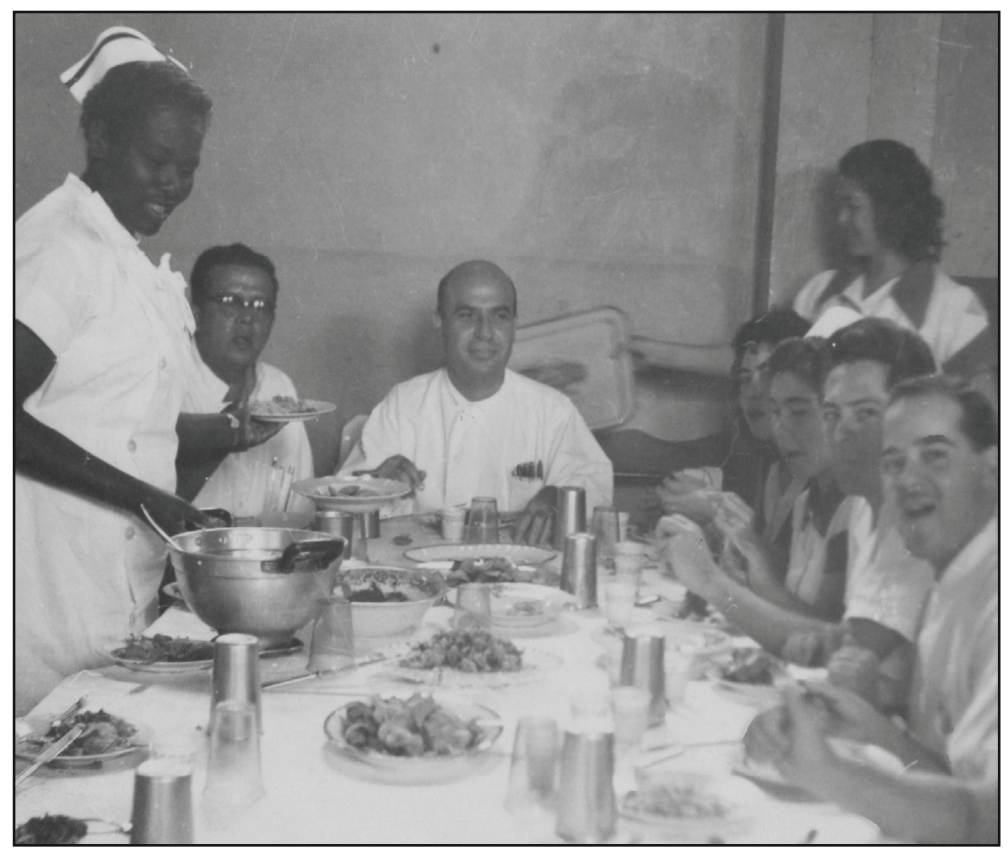

